\title{
Prevalence of symptoms in female Fabry disease patients: a case-control survey
}

\author{
Machtelt G. Bouwman • Saskia M. Rombach • \\ Erica Schenk • Annelies Sweeb • Frits A. Wijburg • \\ Carla E. M. Hollak • Gabor E. Linthorst
}

Received: 29 April 2011 /Revised: 19 December 2011 / Accepted: 27 December 2011 /Published online: 20 March 2012

(C) The Author(s) 2012. This article is published with open access at Springerlink.com

\begin{abstract}
Background Fabry disease (FD) is an X-linked lysosomal storage disorder, caused by a deficiency of $\alpha$-galactosidase A. Several studies demonstrated that heterozygotes have symptoms such as acroparesthesia, abdominal pain and chronic fatigue. However, as these symptoms are aspecific and relatively common in the general population, it is important to compare the prevalence of these symptoms with an appropriate control group. The aim of this study was to explore the prevalence of signs and symptoms in FD females in comparison to a control group.

Methods FD females and age-matched controls were approached to complete a questionnaire. This questionnaire was developed by the Dutch Fabry patient organisation (Fabry Support en Informatie Groep Nederland, FSIGN) with input from Fabry expert-physicians from the AMC.
\end{abstract}

Communicated by: Robert J. Desnick

M. G. Bouwman · F. A. Wijburg

Department of Paediatrics, Academic Medical Center,

Amsterdam, The Netherlands

S. M. Rombach • C. E. M. Hollak · G. E. Linthorst Department of Endocrinology and Metabolism, Academic Medical Center and 'Sphinx' the Amsterdam Lysosome Center,

Amsterdam, The Netherlands

E. Schenk $\cdot$ A. Sweeb

Dutch Fabry Patient Organisation, FSIGN,

Amsterdam, The Netherlands

M. G. Bouwman $(\square)$

Academic Medical Center, Emma Childrens Hospital,

Meibergdreef 9,

1105 AZ, Amsterdam, The Netherlands

e-mail: m.g.bouwman@amc.uva.nl
We compared the prevalence symptoms using Pearson's chi-square test. Bonferroni correction was used to correct for multiple comparisons.

Results A total of 63 heterozygotes and 52 controls completed the questionnaire. Many symptoms were also common in controls. Yet, fatigue, palpitations, pains in hands and feet, joint pain, dizziness, loss of libido and proteinuria during pregnancy were more common in Fabry females (all $\mathrm{p}<0.001)$.

Conclusion In addition to acroparesthesia - fatigue, palpitations, dizziness, proteinuria during pregnancy, libido loss and joint pain are more prevalent in FD females as compared to a control group. Although, these symptoms are present in a significant proportion of normal controls they deserve further attention by treating physicians to better understand their significance, treatment and relationship with FD.

\section{Introduction}

Fabry disease (FD) is a lysosomal storage disorder, caused by a deficiency of the lysosomal enzyme alpha-galactosidase A (Desnick et al. 2001). Accumulation of globotriaosylceramide in vascular cells leads to multiple organ disease, characterised by acroparesthesia, angiokeratoma, progressive renal failure, cardiac complications and stroke. Unlike most lysosomal storage disorders, the inheritance of FD is $\mathrm{X}$-linked and therefore in general heterozygotes have a mosaic state.

Following the availability of enzyme replacement therapy (ERT) in 2001, a number of Fabry cohort studies and post-marketing registry studies have been reported in the literature, describing the natural history of FD in males (Germain et al. 2003; Macdermot et al. 2001a, b; 
Schiffmann 2001), females (Deegan et al. 2006; Guffon 2003; Gupta et al. 2005; Kobayashi et al. 2008; Macdermot et al. 2001a, b; Wang et al. 2007; Whybra et al. 2001; Wilcox et al. 2008) or both (Galanos et al. 2002; Mehta et al. 2004; Schiffmann et al. 2009; Vedder et al. 2007). These studies have shown that despite residual enzyme activity, FD females do develop signs and symptoms of FD, such as left ventricular hypertrophy, proteinuria, stroke and, to a lesser extent, renal failure. The prevalence of acroparesthesia, a well known symptom of Fabry disease, ranges from 23 to $90 \%$ of the patients in the different cohort studies (see Table 5). These studies also reported a high prevalence of other non-specific complaints such as fatigue, palpitations, chest pain, abdominal pain and diarrhoea in FD females (see Table 5). As all of these symptoms are non-specific, care should be taken to attribute them directly to FD, especially as these studies lack control groups. At the outpatient clinic, Fabry females sometimes report symptoms or complaints of which both patient and the treating physician are unsure whether that complaint is part of the clinical spectrum of FD. The only way to appreciate whether certain complaints, aspecific or not, are part of the spectrum of FD is to study their prevalence in comparison with an appropriate control group.

In order to study the spectrum and prevalence of FD related symptoms in FD females, the Dutch Fabry patient organisation (Fabry Support en Informatie Groep Nederland, FSIGN), in collaboration with the lysosomal center 'Sphinx' of the AMC, initiated a questionnaire study on symptoms in FD females and an age matched control group. Based on personal experience of a group of FD females certain symptoms were added to the questionnaire. The purpose of this study was to explore the prevalence of symptoms in FD females compared to controls by use of a questionnaire.

\section{Methods}

Participants and recruitment

Participants for the study were recruited from the Academic Medical Centre, the national referral center for patients with Fabry disease in the Netherlands. We asked all FD females, aged 12 years and older, diagnosed by mutation analysis $(n=81)$ to participate. We sent a letter explaining the aim of the study including two questionnaires.

FD females were asked to fill out one questionnaire (marked "P") and to give one questionnaire to a non-Fabry female friend, neighbour or relative (marked "C"), with approximately the same age. All questionnaires were analysed anonymously. This study was judged by the Ethical Committee of the AMC, Amsterdam as being a non- interventional study, which does not require formal approval under Dutch law and is considered to cause no harm to the study subjects.

\section{Questionnaire}

The questionnaire was developed by two members (ES and AS) of the Dutch Fabry patient organisation (FSIGN) in close collaboration with Fabry expert-physicians (SMR and $\mathrm{CEH}$ ) from the AMC. During a meeting organised and attended by FD females only $(n=20)$, the content of the questionnaire was discussed. Based on personal experience of the attendees, additional symptoms were added that were so far not considered to be part of Fabry symptomatology (see Results, Table 4).

The questionnaire contained general questions on health, sports, smoking, employment and sleeping difficulty (12 questions). Furthermore women were asked on the presence of cardiopulmonary, gastrointestinal, musculoskeletal, neuropsychological, urogenital symptoms and pregnancy outcome (54 questions). Participants were asked to respond yes/no to the presence of these symptoms during the last three months.

\section{Statistical analysis}

All statistical analyses were performed using SPSS version 16.0. Pearson's chi-square test was used to compare the frequency of symptoms in FD females with the frequency in control females. The Fisher's exact test was used when one or more of the cells in the $2 \times 2$ contingency table had an expected frequency of five or less.

Multiple testing may result in false positive results simply due to chance. Therefore, the significance level was adjusted in accordance with the Bonferroni correction (Bland and Altman 1995). To determine the significance level, a p-value of 0.05 was divided by the number of comparisons done $(n=66 ; \mathrm{p}=0.0008)$ (Bland and Altman 1995 ) and was subsequently set at $\mathrm{p}<0.001$. In addition, odds ratios were calculated, but here we used a $95 \%$ confidence interval.

\section{Results}

A total of $62 \mathrm{FD}$ females completed the questionnaire (response rate of $77 \%$ ). In addition 53 female controls participated in the study. The mean age of the FD females was 39 years versus 42 years in controls ( $p=0.67$; Table 1 ). Pearson's chi-square test was used to compare the frequency of symptoms in FD females with the frequency in control females. The results of these analyses are mentioned in Tables 1,2 and 3. There was no difference in 
Table 1 Characteristics of FD females and controls

\begin{tabular}{|c|c|c|c|c|}
\hline & Fabry & Control & OR $(95 \% \mathrm{CI})$ & $\mathrm{p}$ value $^{\mathrm{a}}$ \\
\hline Age & $39.3( \pm 17.5)$ & $41.7( \pm 16.7)$ & NA & $0.67^{\mathrm{b}}$ \\
\hline Employed & $29 / 52(56 \%)$ & $31 / 44(71 \%)$ & $0.53(0.23-1.23)$ & 0.14 \\
\hline Doing sports & $31 / 62(50 \%)$ & $36 / 53(68 \%)$ & $0.47(0.22-1.01)$ & 0.052 \\
\hline Smoking & $8 / 62(13 \%)$ & $10 / 52(19 \%)$ & $0.62(0.23-1.71)$ & 0.36 \\
\hline Drinking alcohol & $30 / 61(49 \%)$ & $33 / 52(64 \%)$ & $0.58(0.26-1.19)$ & 0.13 \\
\hline Not sleeping well $*$ & $32 / 61(53 \%)$ & $14 / 53(26 \%)$ & $3.07(1.39-6.78)$ & 0.005 \\
\hline Not well rested when awake * & $37 / 60(62 \%)$ & $16 / 52(33 \%)$ & $3.62(1.65-7.94)$ & 0.002 \\
\hline Perceived health status as not good & $26 / 61(42 \%)$ & $3 / 52(8 \%)$ & $12.1(3.40-43.3)$ & $\leq 0.001$ \\
\hline Medication & $40 / 62(65 \%)$ & $16 / 52(31 \%)$ & $4.09(1.86-8.98)$ & $\leq 0.001$ \\
\hline Paramedic treatment $*$ & $16 / 62(26 \%)$ & $7 / 53(13 \%)$ & $2.29(0.86-6.08)$ & 0.09 \\
\hline In treatment specialist / general practitioner & $31 / 60(52 \%)$ & $10 / 53(19 \%)$ & $4.60(1.96-10.8)$ & $<0.001$ \\
\hline Health problems * & $40 / 60(67 \%)$ & $18 / 51(35 \%)$ & $3.67(1.67-8.05)$ & 0.001 \\
\hline
\end{tabular}

employment status, smoking, alcohol use and sports participation (Table 1).

Perceived health status was significantly decreased in FD females as 26 patients reported not feeling healthy compared to three controls ( $42 \%$ versus $8 \%$ respectively; $\mathrm{p}<0.001$, OR 12.1). Significantly more patients with FD were prescribed medication, including enzyme replacement therapy $(65 \%$ versus $31 \%$ respectively, $\mathrm{p}<0.001$, OR 4.09; Table 1). In total 28 FD females were treated with ERT (45\%).

\section{Cardiopulmonary symptoms}

Palpitations were reported significantly more often in FD females (48\% versus $13 \%$ in controls, $\mathrm{p}<0.001$, OR 5.96). Almost half of the patients reported to have shortness of breath, although there was no significant difference after Bonferroni correction (Table 2).

\section{Gastrointestinal (GI) symptoms}

GI symptoms were reported often by both FD females and control females, see Table 2. FD females frequently reported nausea, swallowing difficulties, abdominal pain, diarrhoea and constipation. Abdominal pain was reported by $60 \%$ of the FD females. Diarrhoea and constipation were present in $41 \%$ and $34 \%$ respectively. These symptoms were also common in controls (in 30\%, 19\% and 9\% respectively). After adjustment of the p-value with the Bonferroni correction, there were no significant differences in gastrointestinal symptoms between the two groups (nausea: $\mathrm{p}=0.01$; swallowing difficulties: $\mathrm{p}=0.01$; abdominal pain: $p=0.002$; diarrhoea: $p=0.01$ and constipation: $p=0.002$ ). Any GI symptom was mentioned by 51 of the 62 Fabry females versus 27 of the 53 controls ( $82 \%$ versus $51 \%$, $\mathrm{p}<0.001$, Pearson chi square test).
Musculoskeletal symptoms

The results on the neuromuscular symptoms are summarised in Table 2. Joint pain was present in 36 FD females which was significantly more compared to 13 control females ( $58 \%$ versus $25 \%, \mathrm{p}<0.001$, OR 4.15$)$. In addition pain in hands and feet was reported significantly more frequent in FD females (58\% versus $11 \%, \mathrm{p}<0.001$, OR 10.9 and $39 \%$ versus $9 \%$ respectively, $\mathrm{p}<0.001$, OR 6.2).

Neuropsychological symptoms

Dizziness was reported more frequently by FD females (60\% versus $19 \%, p<0.001$, OR 6.36). Fatigue was reported by almost all patients $(n=55)$, but also by many controls $(n=$ 30 ), yet it was significantly more common in FD females (89\% versus $57 \%, \mathrm{p}<0.001$, OR 6.02). No differences were found in other neuropsychological symptoms (see Table 2).

Menstrual cycle

The prevalence of premenstrual, menstrual symptoms and menarche was not different between Fabry females and controls $(\mathrm{p}=0.59, \mathrm{p}=0.42$ and $\mathrm{p}=0.72$ respectively; see Table 2).

Pregnancy related outcome

Thirty-two females with Fabry disease had a history of pregnancy and 35 controls (in total 89 pregnancies in Fabry females, 78 in controls; miscarriages not included). The results are summarised in Table 3. Proteinuria during pregnancy was reported by nearly one third of Fabry females (34\% versus $0 \%, \mathrm{p}<0.001)$ as well as hypertension during pregnancy in FD females, although the latter was not significantly different ( $34 \%$ versus $14 \%, \mathrm{p}=0.05)$. There were 
Table 2 Prevalence of symptoms in FD females and controls

\begin{tabular}{|c|c|c|c|c|c|}
\hline toms in FD females and controls & & Fabry & Control & OR $(95 \% \mathrm{CI})$ & $\mathrm{p}$ value $^{\mathrm{a}}$ \\
\hline & \multicolumn{5}{|l|}{ Cardiopulmonary symptoms } \\
\hline & Palpitations & $29 / 61(48 \%)$ & $7 / 53(13 \%)$ & $5.96(2.32-15.3)$ & $\leq 0.001$ \\
\hline & Skipped heartbeat * & $20 / 60(33 \%)$ & $6 / 53(11 \%)$ & $3.92(1.43-10.7)$ & 0.006 \\
\hline & Chest pain * & $18 / 62(29 \%)$ & $5 / 51(10 \%)$ & $3.76(1.29-11.0)$ & 0.01 \\
\hline & Shortness of breath * & $30 / 62(48 \%)$ & $10 / 53(19 \%)$ & $4.03(1.72-9.43)$ & 0.01 \\
\hline & \multicolumn{5}{|l|}{ Gastrointestinal symptoms } \\
\hline & Regurgitation & $23 / 61(38 \%)$ & $16 / 52(31 \%)$ & $1.36(0.62-2.98)$ & 0.44 \\
\hline & Reflux & $18 / 62(29 \%)$ & $11 / 52(21 \%)$ & $1.52(0.64-3.61)$ & 0.34 \\
\hline & Nausea * & $27 / 62(44 \%)$ & $11 / 53(21 \%)$ & $2.95(1.28-6.77)$ & 0.01 \\
\hline & Swallowing difficulties $*$ & $19 / 61(31 \%)$ & $6 / 53(11 \%)$ & $3.54(1.29-9.71)$ & 0.01 \\
\hline & Hiccup & $25 / 58(43 \%)$ & $18 / 51(35 \%)$ & $1.39(0.64-3.01)$ & 0.40 \\
\hline & Abdominal pain * & $37 / 62(60 \%)$ & $16 / 53(30 \%)$ & $3.42(1.58-7.43)$ & 0.002 \\
\hline & Diarrhoea * & $25 / 61(41 \%)$ & $10 / 53(19 \%)$ & $2.99(1.27-7.03)$ & 0.01 \\
\hline & Constipation * & $21 / 61(34 \%)$ & $5 / 53(9 \%)$ & $5.04(1.74-14.6)$ & 0.002 \\
\hline & Flatulence & $34 / 62(55 \%)$ & $25 / 53(47 \%)$ & $1.36(0.65-2.84)$ & 0.41 \\
\hline & \multicolumn{5}{|l|}{ Musculoskeletal symptoms } \\
\hline & Myalgia * & $35 / 62(57 \%)$ & $19 / 53(36 \%)$ & $2.32(1.09-4.93)$ & 0.03 \\
\hline & Muscle cramps * & $25 / 62(40 \%)$ & $8 / 53(15 \%)$ & $3.80(1.53-9.42)$ & 0.003 \\
\hline & Back ache * & $38 / 61(62 \%)$ & $17 / 53(32 \%)$ & $3.50(1.61-7.60)$ & 0.001 \\
\hline & Joint pain & $36 / 62(58 \%)$ & $13 / 52(25 \%)$ & $4.15(1.86-9.29)$ & $\leq 0.001$ \\
\hline & Pain in hands & $36 / 62(58 \%)$ & $6 / 5311 \%)$ & $10.85(4.04-29.1)$ & $\leq 0.001$ \\
\hline & Pain in feet & $24 / 61(39 \%)$ & $5 / 53(9 \%)$ & $6.23(2.17-17.9)$ & $\leq 0.001$ \\
\hline & \multicolumn{5}{|c|}{ Neuropsychological symptoms } \\
\hline & Loss of strength $*$ & $28 / 62(45 \%)$ & $8 / 53(15 \%)$ & $4.63(1.88-11.4)$ & 0.001 \\
\hline & Numbness & $8 / 61(13 \%)$ & $8 / 53(15 \%)$ & $0.85(0.30-2.44)$ & 0.56 \\
\hline & Fatique & $55 / 62(89 \%)$ & $30 / 53(57 \%)$ & $6.02(2.32-15.7)$ & $\leq 0.001$ \\
\hline & Dizziness & $37 / 62(60 \%)$ & $10 / 53(19 \%)$ & $6.36(2.71-15.0)$ & $\leq 0.001$ \\
\hline & Headache & $36 / 62(60 \%)$ & $24 / 53(45 \%)$ & $1.67(0.80-3.59)$ & 0.12 \\
\hline & Depressed mood & $34 / 62(55 \%)$ & $20 / 51(39 \%)$ & $1.88(0.89-3.99)$ & 0.19 \\
\hline & \multicolumn{5}{|l|}{ Urogenital symptoms } \\
\hline & Urinary incontinence & $16 / 62(26 \%)$ & $12 / 53(23 \%)$ & $1.19(0.50-2.80)$ & 0.69 \\
\hline & Dysuria\# & $3 / 62(4.8 \%)$ & $1 / 53(1.9)$ & $2.64(0.27-26.2)$ & 0.62 \\
\hline & Premenstrual symptoms & $26 / 40(65 \%)$ & $20 / 34(29 \%)$ & $1.30(0.51-3.34)$ & 0.59 \\
\hline & Menstrual symptoms & $24 / 35(67 \%)$ & $23 / 31(74 \%)$ & $0.76(0.26-2.22)$ & 0.42 \\
\hline & Menarche at $12-15$ years & $44 / 62(71 \%)$ & $36 / 53(68 \%)$ & NA & 0.72 \\
\hline & Fertility problems\# & $5 / 40(13 \%)$ & $1 / 39(2.6 \%)$ & $5.43(0.60-48.8)$ & 0.20 \\
\hline & Loss of libido & $27 / 45(60 \%)$ & $9 / 31(23 \%)$ & $3.67(1.38-9.75)$ & $<0.001$ \\
\hline & \multicolumn{5}{|l|}{ Dermatological symptoms } \\
\hline & Dry skin* & $42 / 61(68 \%)$ & $25 / 53(47 \%)$ & $2.48(1.15-5.32)$ & 0.03 \\
\hline & Acne & $10 / 61(16 \%)$ & $6 / 53(11 \%)$ & $1.54(0.52-4.55)$ & 0.44 \\
\hline & Eczema & $11 / 62(18 \%)$ & $7 / 53(13 \%)$ & $1.42(0.51-3.96)$ & 0.50 \\
\hline & Vitiligo & $6 / 62(10 \%)$ & $5 / 53(9 \%)$ & $1.03(0.21-3.58)$ & 0.97 \\
\hline & Urticaria\# & $3 / 61(4.9 \%)$ & $2 / 52(3.8 \%)$ & $1.29(0.21-8.05)$ & 1.00 \\
\hline \multirow{4}{*}{$\begin{array}{l}\text { Data are number }(\%) . \mathrm{OR}=\text { odds } \\
\text { ratio. Bold: significant } \\
\text { after Bonferroni correction. } \\
* \mathrm{p}<0.05 .\end{array}$} & \multicolumn{5}{|l|}{ Other symptoms } \\
\hline & Hypohidrosis* & $17 / 59(29 \%)$ & $5 / 51(10 \%)$ & $3.72(1.26-11.0)$ & 0.01 \\
\hline & Spontaneous tear in molar & $13 / 60(22 \%)$ & $10 / 49(20 \%)$ & $1.08(0.43-2.73)$ & 0.87 \\
\hline & Allergy & $10 / 62(16 \%)$ & $9 / 53(17 \%)$ & $0.94(0.35-2.52)$ & 0.90 \\
\hline \multirow{2}{*}{$\begin{array}{l}\text { a according to Pearson chi-square } \\
\text { test. \# Fisher's exact test because } \\
\text { of small sample size. }\end{array}$} & Snoring & $20 / 62(32 \%)$ & $31 / 53(56 \%)$ & $0.34(0.16-0.73)$ & 0.30 \\
\hline & Gum disease* & $16 / 62(26 \%)$ & $6 / 53(11 \%)$ & $2.72(0.98-7.58)$ & 0.05 \\
\hline
\end{tabular}

Data are number $(\%) . \mathrm{OR}=$ odds ratio. Bold: significant after Bonferroni correction.

$* \mathrm{p}<0.05$.

a according to Pearson chi-square test. \# Fisher's exact test because of small sample size. 
Table 3 Pregnancy and pregnancy outcome in FD females and controls
Data are numbers (\%). OR = odds ratio. Bold: significant after Bonferroni correction. NA = not applicable. ${ }^{\text {a According to }}$ Pearson chi-square test. \# Fisher's exact test because of small sample size.

\begin{tabular}{lllll}
\hline & Fabry $(\mathrm{n}=62)$ & Control $(\mathrm{n}=53)$ & OR $(95 \% \mathrm{CI})$ & $\mathrm{p} \mathrm{value}^{\mathrm{a}}$ \\
\hline Pregnancy outcome & & & & \\
Hypertension during pregnancy \# & $11 / 32(34 \%)$ & $5 / 35(14 \%)$ & $3.14(0.95-10.4)$ & 0.05 \\
Proteinuria during pregnancy & $11 / 32(34 \%)$ & $0 / 35(0 \%)$ & $\mathrm{NA}$ & $<0.001$ \\
Preeclampsia \# & $3 / 32(9.4 \%)$ & $0 / 35(0 \%)$ & $\mathrm{NA}$ & 0.10 \\
Premature delivery \# & $6 / 32(19 \%)$ & $2 / 35(5.7 \%)$ & $3.81(0.71-20.4)$ & 0.14 \\
Induced labour & $7 / 32(22 \%)$ & $5 / 35(14 \%)$ & $1.68(0.47-5.95)$ & 0.42 \\
Pelvic instability \# & $2 / 32(6.2 \%)$ & $4 / 35(11 \%)$ & $0.52(0.09-3.03)$ & 0.68 \\
Microsomia \# & $3 / 32(9.4 \%)$ & $1 / 35(2.9 \%)$ & $3.52(0.35-35.7)$ & 0.34 \\
Macrosomia \# & $1 / 32(3.1 \%)$ & $1 / 35(2.9 \%)$ & $1.10(0.07-18.3)$ & 1.00 \\
Postpartum bleeding \# & $3 / 32(9.4 \%)$ & $5 / 35(15 \%)$ & $0.62(0.14-2.84)$ & 0.71 \\
Retained placenta \# & $4 / 32(13 \%)$ & $6 / 35(17 \%)$ & $0.69(0.18-2.71)$ & 0.74 \\
Miscarriage & $8 / 32(25 \%)$ & $4 / 35(11 \%)$ & $2.58(0.69-9.61)$ & 0.15 \\
Intrauterine death & $1 / 32(3.1 \%)$ & $1 / 35(2.9 \%)$ & $1.10(0.07-18.3)$ & 1.00 \\
\hline
\end{tabular}

\section{Discussion}

(9.4\% versus $0 \%, \mathrm{p}=0.10)$ miscarriages $(25 \%$ versus $11 \%$, $\mathrm{p}=0.15)$, fertility problems ( $(13 \%$ versus $2.6 \%, \mathrm{p}=0.20)$ and premature delivery in FD females and controls (19\% versus $6 \%, \mathrm{p}=0.14)$. In addition, intrauterine death did not occur more often in the studied group ( $3 \%$ versus $3 \%, p=1.0)$.

\section{Other symptoms}

Loss of libido was also reported significantly more common by FD females than controls ( $60 \%$ vs. $23 \%, \mathrm{p}<0.001$, OR 3.67). Loss of libido was not significantly related to fatigue in both FD females $(p=0.38)$ and non-FD females $(p=0.06)$. Twenty-nine percent (17/59) of the FD females had hypohidrosis (versus $10 \%$ in controls $5 / 51, \mathrm{p}=0.01$ ) (see Table 2 ). Table 4 shows the frequency of occurence of symptoms suggested specifically by Fabry females to be included in the questionnaire.
In this exploratory study we compared the prevalence of both classical FD related symptoms as well as a variety of other complaints in a large cohort of FD females with prevalence of these symptoms in a well matched control group. This study confirms that some previously described symptoms are significantly more common in Fabry females. Pain in hands and feet, acroparesthesia, are indeed a common symptom in FD females. The prevalence of acroparesthesia in the current study is higher than previously reported by us in a smaller cohort (Vedder et al. 2007), and is in agreement with the overall prevalence of $61 \%$ (range 23 90\%) in several other studies (see Tables 2 and 5). Palpitations were also significantly more common in FD females. Fatigue was the most commonly reported symptom (89\%), as was also reported by Mac Dermot et al. (Macdermot et al.
Table 4 Symptoms suggested by Fabry females: FD females versus controls

Data are numbers $(\%) . \mathrm{OR}=$ odds ratio. $*=\mathrm{p}<0.05$. ${ }^{\text {a }}$ according to Pearson chi-square test

\begin{tabular}{lllll}
\hline & Fabry $(\mathrm{n}=62)$ & Control $(\mathrm{n}=53)$ & OR $(95 \% \mathrm{CI})$ & $\mathrm{p} \mathrm{value}^{\mathrm{a}}$ \\
\hline Not sleeping well * & $32 / 61(53 \%)$ & $14 / 53(26 \%)$ & $3.07(1.39-6.78)$ & 0.005 \\
Not well rested when awake * & $37 / 60(62 \%)$ & $16 / 52(33 \%)$ & $3.62(1.65-7.94)$ & 0.002 \\
Snoring & $20 / 62(32 \%)$ & $31 / 53(56 \%)$ & $0.34(0.16-0.73)$ & 0.30 \\
Headache & $36 / 62(60 \%)$ & $24 / 53(45 \%)$ & $1.74(0.83-3.66)$ & 0.12 \\
Flatulence & $34 / 62(55 \%)$ & $25 / 53(47 \%)$ & $1.36(0.65-2.84)$ & 0.41 \\
Hiccup & $25 / 58(43 \%)$ & $18 / 51(35 \%)$ & $1.39(0.64-3.01)$ & 0.40 \\
Myalgia * & $35 / 62(57 \%)$ & $19 / 53(36 \%)$ & $2.32(1.09-4.93)$ & 0.027 \\
Muscle cramps * & $25 / 62(40 \%)$ & $8 / 53(15 \%)$ & $3.80(1.53-9.42)$ & 0.003 \\
Dry skin* & $67.6(42 / 61)$ & $47.2(25 / 53)$ & $2.48(1.15-5.32)$ & 0.03 \\
Acne & $16.4(10 / 61)$ & $11.3(6 / 53)$ & $1.54(0.52-4.55)$ & 0.44 \\
Eczema & $17.7(11 / 62)$ & $13.2(7 / 53)$ & $1.42(0.51-3.96)$ & 0.50 \\
Vitiligo & $9.7(6 / 62)$ & $9.4(5 / 53)$ & $1.03(0.30-3.58)$ & 0.97 \\
Spontaneous tear in molar & $21.7(13 / 60)$ & $20.4(10 / 49)$ & $1.08(0.43-2.73)$ & 0.87 \\
Allergy & $16.1(10 / 62)$ & $17.0(9 / 53)$ & $0.94(0.35-2.52)$ & 0.90 \\
Gum disease & $25.8(16 / 62)$ & $11.3(6 / 53)$ & $2.72(0.98-7.58)$ & 0.05 \\
\hline
\end{tabular}




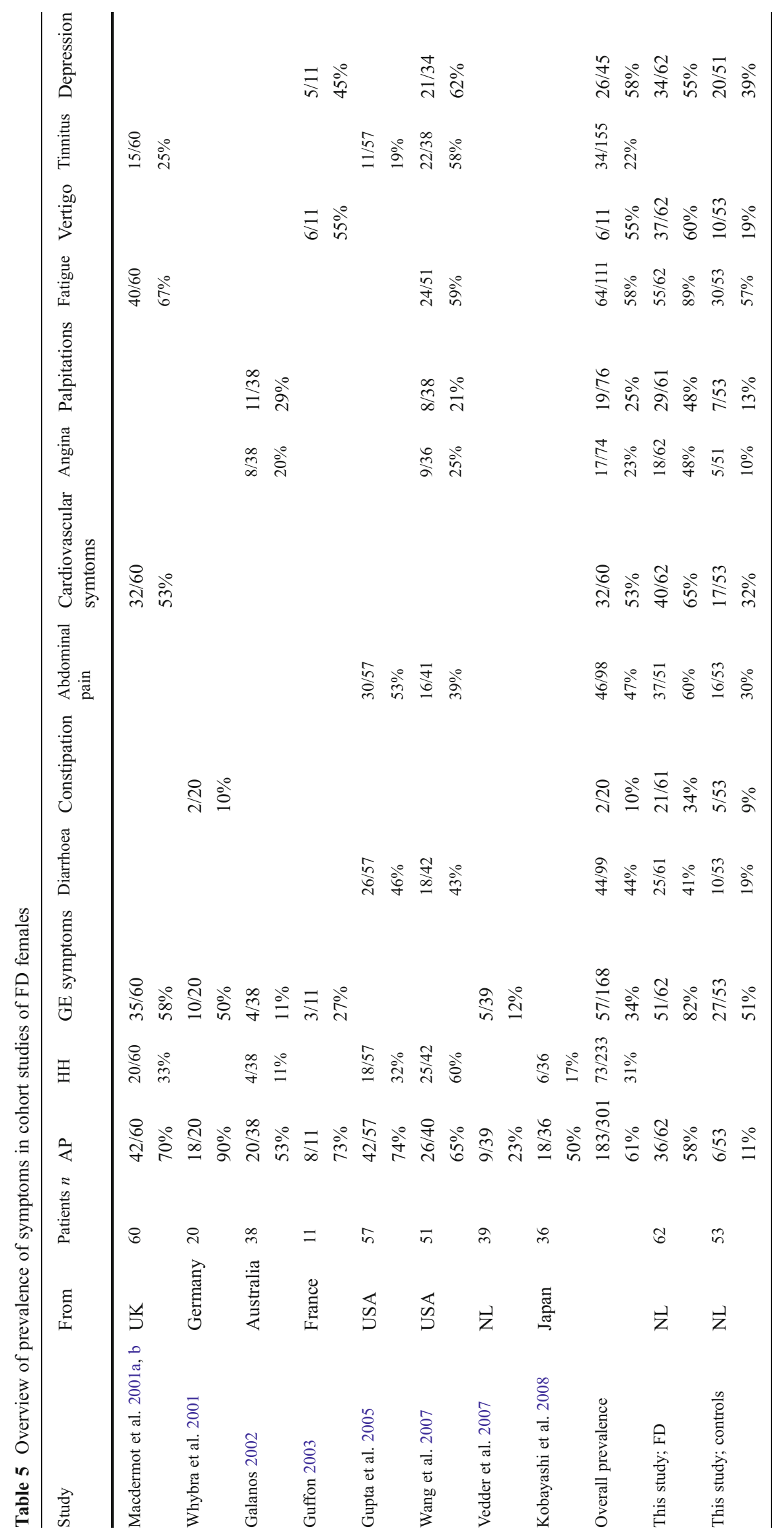


2001a, b). Although, as may be expected, a substantial proportion of normal controls also experienced chronic fatigue (57\%), this was significantly more prevalent in the FD females. In addition to the more common FD attributed symptoms, this study also confirms a higher prevalence of symptoms of joint pain and dizziness in FD females as compared to controls.

A high prevalence of gastro-intestinal symptoms was observed (any GI symptom was mentioned by $82 \%$ of the Fabry females, versus $51 \%$ in controls). However, none of these individual symptoms were significantly more prevalent in the Fabry disease group with a threshold of $p<0.001$ following the Bonferonni correction for multiple comparisons. Nevertheless, five of the nine gastro-intestinal symptoms that were included in the questionnaire were more common in FD females with a p-value of $<0.05$, with odds ratios ranging from 3 to 5 (Table 2). We feel therefore that it is unlikely that this is completely due to chance and suggests that the gastrointestinal tract is indeed affected in FD females. In other studies the overall prevalence of gastro-intestinal symptoms in FD females was 34\% (range 11-58\%). In one large cohort study the prevalence of GI symptoms was $58 \%$, and consisted of complaints of bloating, indigestion and abdominal cramps (Macdermot et al. 2001a, b). A previous smaller study by our group revealed only a prevalence of $12 \%$ in the female Fabry patients (Vedder et al. 2007). The differences in prevalence between that study and the current one could be due to difference in methods used (questionnaire versus physicians' interpretation). The fact that we also observed a high prevalence of gastro-intestinal symptoms in controls (51\%) emphasises the need to include a control group, especially when evaluating the prevalence of non-specific symptoms.

This study has identified several potentially FD related symptoms that were previously not recognised. This may be relevant for both FD females and their treating physicians. First, our results indicate that there is a high prevalence of proteinuria during pregnancy in FD females. It cannot be made clear from this study whether these patients had proteinuria before pregnancy, which was subsequently revealed during pregnancy or that Fabry females are more prone to develop proteinuria during pregnancy. However, this finding deserves further study. So far, only case-studies on uneventful pregnancies have been reported (Bouwman et al. 2010; Germain et al. 2010; Kalkum et al. 2009; Parent et al. 2010; Politei 2010; Wendt et al. 2005). The prevalence of hypertension during pregnancy and pre-eclampsia was slightly increased in Fabry females, although not to a statistically significant level in this relatively small group. Its exact pathophysiological mechanism remains unclear. We suggest that complications during pregnancy and pregnancy outcome should be studied in a larger cohort of FD females.

In the current study, we found a high prevalence of loss of libido. This may well be caused by the presence of a chronical medical condition (Simon 2010) and therefore not necessarily be Fabry-specific. Nevertheless it is important for physicians treating FD females to acknowledge presence of this symptom.

A limitation of the current study is that we used a nonvalidated questionnaire specifically developed for this study. Though a variety of symptoms were evaluated, this questionnaire might not have covered all possible signs and symptoms. Another limitation of the study is the way controls were selected, as this was a patient selected group of friends, neighbours or relatives, and controls were not randomly selected. However, this approach also has advantages, as it generates a control group which is similar in several important respects, such as socioeconomic status and education. In addition, the groups did not differ in age and the controls included in the study were not only healthy individuals. We decided not to stratify for age and treatment with ERT, to prevent additional testing. However, these are important confounders. In general we found that patients treated with ERT had more symptoms and were generally older than patients not on ERT (data not shown). Finally, we confirm that fatigue, palpitations, pains in hands and feet, dizziness and joint pain are more prevalent in FD females as compared to a control group. Although, these symptoms are present in a significant proportion of normal controls they deserve further attention by treating physicians and researchers to better understand their significance, treatment and possible relationship with FD.

Acknowledgements Mrs E. Ormel is acknowledged for her support. We acknowledge the collaboration of the Fabry disease females who collaborated with the AMC study team and those that participated in the study.

On request a translated version of the questionnaire can be obtained through the Dutch Fabry patient organisation (Fabry Support en Informatie Groep Nederland, FSIGN, FSIGN@fabry.nl)

Conflicts of interest G.E.L., C.E.M.H., and F.A.W. have received reimbursement of travel expenses and honoraria for lectures on the management of lysosomal storage diseases, including Fabry disease, from Genzyme Corporation and Shire HGT, pharmaceutical companies producing enzyme replacement therapy for Fabry disease. G.E.L., and C.E.M.H. donated all honoraria to the Gaucher Foundation, an organization that support research in lysosomal storage diseases. The other authors declare no conflicts of interest.

Open Access This article is distributed under the terms of the Creative Commons Attribution License which permits any use, distribution, and reproduction in any medium, provided the original author(s) and the source are credited.

\section{References}

Bland JM, Altman DG (1995) Multiple significance tests: the Bonferroni method. BMJ 310(6973): 170

Bouwman MG, Hollak CE, van den Bergh Weerman MA, Wijburg FA, Linthorst GE (2010) Analysis of placental tissue in Fabry disease with and without enzyme replacement therapy. Placenta 31(4):344-346 
Deegan PB, Baehner AF, Barba Romero MA, Hughes DA, Kampmann C, Beck M (2006) Natural history of Fabry disease in females in the Fabry outcome survey. J Med Genet 43(4):347-352

Desnick RJ, Ioannou YA, Eng CM (2001) A-galactosidase A deficiency: Fabry disease. In: Scriver CR, Beaudet AL, Sly WS, Valle D (eds) The metabolic and molecular bases of inherited disease, 8th edn. McGraw-Hill, NewYork, pp 3733-3774

Galanos J, Nicholls K, Grigg L, Kiers L, Crawford A, Becker G (2002) Clinical features of Fabry's disease in Australian patients. Intern Med J 32(12):575-584

Germain DP, Avan P, Chassaing A, Bonfils P (2003) Patients affected with Fabry disease have an increased incidence of progressive hearing loss and sudden deafness: an investigation of twenty-two hemizygous male patients. BMC Med Genet 2002 October 11;3:10.Guffon N. Clinical presentation in female patients with Fabry disease. J Med Genet 40(4):e38

Germain DP, Bruneval P, Tran TC, Balouet P, Richalet B, Benistan K (2010) Uneventful pregnancy outcome after enzyme replacement therapy with agalsidase beta in a heterozygous female with Fabry disease: a case report. Eur J Med Genet 53(2):111-112

Guffon N (2003) Clinical presentation in female patients with Fabry disease. J Med Genet 40(4):e38.

Gupta S, Ries M, Kotsopoulos S, Schiffmann R (2005) The relationship of vascular glycolipid storage to clinical manifestations of Fabry disease: a cross-sectional study of a large cohort of clinically affected heterozygous women. Medicine (Baltimore) 84(5):261268

Kalkum G, Macchiella D, Reinke J, Kolbl H, Beck M (2009) Enzyme replacement therapy with agalsidase alfa in pregnant women with Fabry disease. Eur J Obstet Gynecol Reprod Biol 144(1):92-93

Kobayashi M, Ohashi T, Sakuma M, Ida H, Eto Y (2008) Clinical manifestations and natural history of Japanese heterozygous females with Fabry disease. J Inherit Metab Dis

Macdermot KD, Holmes A, Miners AH (2001a) Anderson-Fabry disease: clinical manifestations and impact of disease in a cohort of 60 obligate carrier females. J Med Genet 38(11):769-775

Macdermot KD, Holmes A, Miners AH (2001b) Anderson-Fabry disease: clinical manifestations and impact of disease in a cohort of 98 hemizygous males. J Med Genet 38(11):750-760
Mehta A, Ricci R, Widmer U, Dehout F, de Garcia LA, Kampmann C, Linhart A, Sunder-Plassmann G, Ries M, Beck M (2004) Fabry disease defined: baseline clinical manifestations of 366 patients in the Fabry outcome survey. Eur J Clin Invest 34(3):236-242

Parent E, Wax JR, Smith W, Blaszyk H, Pinette MG, Cartin A, Blackstone J (2010) Fabry disease complicating pregnancy. J Matern Fetal Neonatal Med 23(10):1253-1256

Politei JM (2010) Treatment with agalsidase beta during pregnancy in Fabry disease. J Obstet Gynaecol Res 36(2):428-429

Schiffmann R (2001) Natural history of Fabry disease in males: preliminary observations. J Inherit Metab Dis 24(Suppl 2):15-17

Schiffmann R, Warnock DG, Banikazemi M, Bultas J, Linthorst GE, Packman S, Sorensen SA, Wilcox WR, Desnick RJ (2009) Fabry disease: progression of nephropathy, and prevalence of cardiac and cerebrovascular events before enzyme replacement therapy. Nephrol Dial Transplant 24(7):2102-2111

Simon JA (2010) Low sexual desire-is it all in her head? Pathophysiology, diagnosis, and treatment of hypoactive sexual desire disorder. Postgrad Med 122(6):128-136

Vedder AC, Linthorst GE, van Breemen MJ, Groener JE, Bemelman FJ, Strijland A, Mannens MM, Aerts JM, Hollak CE (2007) The Dutch Fabry cohort: diversity of clinical manifestations and Gb3 levels. J Inherit Metab Dis 30(1):68-78

Wang RY, Lelis A, Mirocha J, Wilcox WR (2007) Heterozygous Fabry women are not just carriers, but have a significant burden of disease and impaired quality of life. Genet Med 9(1):34-45

Wendt S, Whybra C, Kampmann C, Teichmann E, Beck M (2005) Successful pregnancy outcome in a patient with Fabry disease receiving enzyme replacement therapy with agalsidase alfa. J Inherit Metab Dis 28(5):787-788

Whybra C, Kampmann C, Willers I, Davies J, Winchester B, Kriegsmann J, Bruhl K, Gal A, Bunge S, Beck M (2001) Anderson-Fabry disease: clinical manifestations of disease in female heterozygotes. J Inherit Metab Dis 24(7):715-724

Wilcox WR, Oliveira JP, Hopkin RJ, Ortiz A, Banikazemi M, FeldtRasmussen U, Sims K, Waldek S, Pastores GM, Lee P, Eng CM, Marodi L, Stanford KE, Breunig F, Wanner C, Warnock DG, Lemay RM, Germain DP (2008) Females with Fabry disease frequently have major organ involvement: lessons from the Fabry Registry. Mol Genet Metab 93(2):112-128 